This article represents an exciting new future for a worldwide disease that has no curative treatment or targeted therapy capable of reversing or halting progression of the inciting pathology. ${ }^{9}$ Is it possible that an ischemic heart could heal itself if we just provide the right supplies? Time will tell, but this study by Selke and colleagues ${ }^{1}$ suggests that fibrosis from ischemic heart disease has the potential to be reversed.

\section{References}

1. Aboulgheit AM, Karbasiafshar C, Sabra M, Zhang Z, Sodha N, Abid MR, Sellke F. Extracellular vesicles improve diastolic function and substructure in normal and high-fat diet models of chronic myocardial ischemia. J Thorac Cardiovasc Surg. 2022;164:e371-84.

2. Aboulgheit A, Potz BA, Scrimgeour LA, Karbasiafshar C, Shi G, Zhang Z, et al. Effects of high fat versus normal diet on extracellular vesicle-induced angiogenesis in a swine model of chronic myocardial ischemia. J Am Heart Assoc. 2021;10: e017437.

3. Scrimgeour LA, Potz BA, Aboul Gheit A, Shi G, Stanley M, Zhang Z, et al. Extracellular vesicles promote arteriogenesis in chronically ischemic myocardium in the setting of metabolic syndrome. J Am Heart Assoc. 2019;8:1-14.

4. Zhang X, Lerman LO. Investigating the metabolic syndrome: contributions of swine models. Toxicol Pathol. 2016;44:358-66.

5. Roth GA, Johnson C, Abajobir A, Abd-Allah F, Abera SF, Abyu G, et al. Global, regional, and national burden of cardiovascular diseases for 10 causes, 1990 to 2015. J Am Coll Cardiol. 2017;70:1-25.

6. Davidson SM, Yellon DM. Exosomes and cardioprotection-a critical analysis. Mol Aspects Med. 2018;60:104-14.

7. Karbasiafshar C, Sellke FW, Abid MR. Mesenchymal stem cell-derived extracellular vesicles in the failing heart: past, present, and future. Am J Physiol Circ Physiol. 2021;320:H1999-2010.

8. Kuznetsova T, Herbots L, López B, Jin Y, Richart T, Thijs L, et al. Prevalence of left ventricular diastolic dysfunction in a general population. Circ Heart Fail. 2009;2:105-12.

9. Mandinov L, Eberli FR, Seiler C, Hess OM. Diastolic heart failure. Cardiovasc Res. 2000;45:813-25.

\title{
Commentary: Cell therapy goes subcellular
}

\author{
Vaibhav B. Patel, $\mathrm{PhD},{ }^{\mathrm{a}, \mathrm{b}}$ and \\ Paul W. M. Fedak, MD, PhD, FRCSC ${ }^{\text {,c }}$
}

Maladaptive structural cardiac remodeling and resultant clinical heart failure associated with ischemic heart disease is a global burden on health care systems. Contemporary pharmacologic therapies combined with surgical revascularization improves patient survival but fails to prevent fibrotic scar formation and replace lost cardiomyocytes. ${ }^{1}$ Stem cell therapy repopulates damaged myocardium and offers the promise of replacing lost contractile elements to restore function and prevent heart failure. However, the benefits of cell-based therapies shown in animal models are poorly translated when applied to human patients. Enthusiasm for cell clinical cardiovascular therapy is

From the ${ }^{\mathrm{a} D e p a r t m e n t ~ o f ~ P h y s i o l o g y ~ a n d ~ P h a r m a c o l o g y, ~ a n d ~}{ }^{\mathrm{c}}$ Section of Cardiac Surgery, Department of Cardiac Sciences, Cumming School of Medicine, and ${ }^{\mathrm{b}}$ Libin Cardiovascular Institute, University of Calgary, Calgary, Alberta, Canada.

Disclosures: The authors reported no conflicts of interest.

The Journal policy requires editors and reviewers to disclose conflicts of interest and to decline handling or reviewing manuscripts for which they may have a conflict of interest. The editors and reviewers of this article have no conflicts of interest.

Received for publication Sept 7, 2021; revisions received Sept 7, 2021; accepted for publication Sept 7, 2021; available ahead of print Sept 9, 2021.

Address for reprints: Paul W. M. Fedak, MD, PhD, FRCSC, C849, 1403-29 St NW, Calgary, Alberta, Canada T2N 2T9 (E-mail: paul.fedak@gmail.com).

J Thorac Cardiovasc Surg 2022;164:e386-7

$0022-5223 / \$ 36.00$

Copyright (c) 2021 by The American Association for Thoracic Surgery

https://doi.org/10.1016/j.jtcvs.2021.09.004

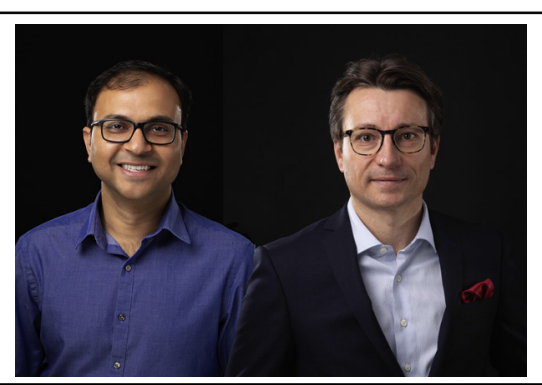

Vaibhav B. Patel, PhD, and Paul W. M. Fedak, MD, PhD, FRCSC

CENTRAL MESSAGE

Extracellular vesicle-based thera-

peutics show potent cardiopro-

tection in a clinically relevant and

unique large animal model of

chronic ischemic heart disease

with diastolic dysfunction.

tempered by numerous translational barriers such as poor survival of the engrafted cells, induction of arrhythmias, and allorejection. ${ }^{2}$ Paracrine mediators released by stem cells are increasingly recognized to drive the beneficial effects of cell therapies, suggesting that the cells themselves may not be necessary to achieve novel subcellular-based therapies. $^{3}$

Extracellular vesicles (EVs) are a heterogeneous group of lipid-bound particles produced and secreted by various 
cells. EVs transport functional miRNAs, proteins, mRNAs, and lipids and play a key role in paracrine intercellular communication. ${ }^{4,5}$ Emerging evidence suggests that EVs could mediate some of the paracrine effects of stem cells. In this issue of the Journal, Aboulgheit and colleagues ${ }^{6}$ investigate the therapeutic effects of EVs derived from human bone marrow-derived mesenchymal stem cells. The study employed a unique swine model of myocardial ischemia with an underlying metabolic syndrome. This highly relevant preclinical model is a major strength of the work, particularly given the poor translation of cell therapy studies in human patients. The high-fat diet swine developed chronic myocardial ischemia with hypertension, dyslipidemia, and hyperglycemia. Administration of EVs by intramyocardial injections improved diastolic function and reduced cardiac fibrosis. This novel subcellular therapeutic avoids immunogenicity and immunorejection, which hampers translation of cell-based therapies.

While an important proof-of-concept is established, the precise mechanisms underlying these benefits are less clear. EVs are a heterogeneous population of particles (exosomes and microvesicles). Determining the precise elements driving the therapeutic responses observed will be essential to limit side effects and optimize the efficacy of the proposed therapy. Identifying the exact molecules responsible for the cardioprotective roles of EVs will facilitate the bioengineering of EVs with the desired cargo to target specific vascular and cardiac repair pathways for diverse etiologies.

Late-stage events associated with coronary heart disease, including myocardial infarction, still account for $\approx 16 \%$ of global mortality and are forecasted to increase. ${ }^{7}$ Currently, therapies for heart failure after myocardial infarction are limited, particularly heart failure with preserved ejection fraction. One of the most exciting aspects of this study is the therapeutic benefit observed with diastolic dysfunction and myocardial extracellular matrix remodeling, the vexing problem of tissue fibrosis. Contemporary therapies poorly address tissue fibrosis. Such novel subcellular approaches may be game-changers if their preclinical effects can be leveraged in our patient population. The excellent model employed in this study increases confidence.

Good research starts with good questions and leads to more questions. Are these tiny subcellular particles ready for the big task we will ask of them? More research is needed.

\section{References}

1. Fedak PW, Verma S, Weisel RD, Skrtic M, Li RK. Cardiac remodeling and failure: from molecules to man (part III). Cardiovasc Pathol. 2005;14:109-19.

2. Karantalis V, Hare JM. Use of mesenchymal stem cells for therapy of cardiac disease. Circ Res. 2015;116:1413-30.

3. Fedak PW. Paracrine effects of cell transplantation: modifying ventricular remodeling in the failing heart. Semin Thorac Cardiovasc Surg. 2008;20:87-93.

4. van Niel G, D'Angelo G, Raposo G. Shedding light on the cell biology of extracellular vesicles. Nat Rev Mol Cell Biol. 2018;19:213-28.

5. Jadli AS, Ballasy N, Edalat P, Patel VB. Inside(sight) of tiny communicator: exosome biogenesis, secretion, and uptake. Mol Cell Biochem. 2020;467: 77-94.

6. Aboulgheit AM, Karbasiafshar C, Sabra M, Zhang Z, Sodha N, Abid MR, Sellke F. Extracellular vesicles improve diastolic function and substructure in normal and high-fat diet models of chronic myocardial ischemia. J Thorac Cardiovasc Surg. 2022;164:e371-84.

7. GBD 2017 DALYs, HALE Collaborators. Global, regional, and national disability-adjusted life-years (DALYs) for 315 diseases and injuries and healthy life expectancy (HALE), 1990-2015: a systematic analysis for the Global Burden of Disease Study 2015. Lancet. 2016;388:1603-58. 